\title{
Do atmospheric teleconnection patterns influence rainfall erosivity? A study of NAO, MO and WeMO in NE Spain,
} 1955-2006.

\author{
M. Angulo-Martínez ${ }^{1^{*}}$, S. Beguería ${ }^{1}$ \\ [1] \{Department of Soil and Water, Estación Experimental de Aula Dei-Consejo Superior de \\ Investigaciones Científicas (EEAD-CSIC). 1005 Avda. Montañana, 50080-Zaragoza (Spain)\} \\ Correspondence to: M. Angulo-Martínez (mangulo@eead.csic.es)
}

\section{Abstract}

Rainfall erosivity is the ability of precipitation to erode soil. Raindrops impact on the surface_rainsplash—represents an important mechanism of soil particles detachment. If the soil is not perfectly flat rainsplash will also produce the movement of soil particles down the slope due to diffusion. But even in the case of flat soils the detached particles will be available for transport by other erosion agents such as surface runoff. Despite its importance as fundamental erosion process very few studies have addressed the climatology of rainfall erosivity. It is known fact rainfall erosivity in long term (e.g., cumulative annual values) is determined by a few number of heavy events. This study analyses the interannual variability of daily rainfall erosivity in NE Spain during the period 1955-2006, and its connection with atmospheric circulation patterns influencing rainfall in the region, namely the North Atlantic Oscillation (NAO), the Mediterranean Oscillation (MO) and the Western Mediterranean 
Oscillation (WeMO). It is found that the erosive power of rainfall is stronger during negative phases of the three atmospheric circulation indices, and weaker during positive conditions. Daily rainfall erosivity series were adjusted to a Generalized Pareto probability distribution for positive and negative days of the atmospheric circulation indices, for assessing their effects on rainfall erosivity extreme events. Results showed higher values expected for a given return period in most of the area under negative conditions of all indices, especially at the Mediterranean coast. Overall, MO and WeMO showed the strongest influence on daily rainfall erosivity extremes. These findings would be useful in the implementation of soil conservation strategies.

Keywords: Rainfall Erosivity; NAO; MO; WeMO; RUSLE $R$ factor; Ebro; NE Spain

\section{Introduction}

The concept of rainfall erosivity refers to the ability of any rainfall event to erode soil. It links the physical properties of raindrops as a consequence of rainfall-generating processes to their impact on the soil surface, and involves mainly two mechanisms: i) rain splash-the detachment of soil particles due to raindrops kinetic energy-, and ii) runoff erosion-soil particles motion by the shear stress exerted by surface runoff. Rainfall erosivity is responsible for changes in soil properties due to crusting, disruption of aggregates, removal of nutrientrich particles, etc. Rainfall erosivity represents one of the main mechanisms of soil degradation in semiarid landscapes where vegetation is scarce. Its influence depends on the soil characteristics, topography and land use, as well as on other features of the rainfall regime (D’Odorico et al. 2001). Rainfall erosivity estimates are thus of paramount importance for the 
estimation of soil erosion rates through space and time. In the context of climate change the effect of altered rainfall characteristics combined with other aspects such as biomass and changes in the soil moisture regime are some major concerns of soil conservation studies.

Rainfall erosivity can be quantified by several erosivity indices that evaluate the relationship between drop size distribution (DSD) and kinetic energy of a given storm. Empirical studies have demonstrated an exponential relationship between rainfall intensity and rainfall erosivity parameters (Brown and Foster 1987; Coutinho and Tomás 1995; Van Dijk et al. 2002). However, since DSD and kinetic energy are highly variable in time and space, and therefore so is rainfall erosivity (Angulo-Martínez et al. 2009), high time resolution series of rainfall intensity are required.

The USLE/RUSLE $R$ factor (MJ mm ha ${ }^{-1} \mathrm{~h}^{-1} \mathrm{y}^{-1}$ ), which is the average value of the annual cumulative $E I_{30}$ index over a period of time (Wischmeier 1959, Wischmeier and Smith 1978, Brown and Foster 1987, Renard et al. 1997), is probably the most widely used rainfall erosivity index. The event's rainfall erosivity $E I_{30}$ index $\left(\mathrm{MJ} \mathrm{mm} \mathrm{ha}{ }^{-1} \mathrm{~h}^{-1}\right)$ is obtained from the energy of the rain $(E)$, given by the unit rainfall energy $e$ (which is an empirical exponential relationship depending on the intensity) per volume of precipitation during a period of 15 minutes, and multiplied by the maximum intensity in 30 minutes. This last multiplication assures that soil saturation and associated surface runoff generation are taken into account.

One of the practical problems associated with the $E I_{30}$ index is the need for high frequencytypically higher than 15 min, or pluviograph data-, long series of rainfall intensity data. Information of this nature is rarely available with the adequate spatial and temporal coverage, and daily records are usually the best available data at most locations. Attempts at estimating rainfall erosivity from daily rainfall records or storm event data have been based largely on exponential relationships (Richardson et al. 1983, Bagarello and D’Asaro 1994, Petkovsek and Mikos 2004, Yin et al. 2007, Capolongo et al. 2008, Angulo-Martínez and Beguería 2009). 
Other attempts to predict rainfall erosivity from mean annual rainfall and/or mean monthly rainfall like the modified Fournier index (Arnoldus 1977) have provided coarse results, since rainfall erosivity depends largely on short but very intense rain episodes, which are largely smoothed when data is aggregated at coarser time resolutions. Despite this drawback, studies based on these indices have been extensively cited in the scientific literature (Banasik and Górski 1994, Renard and Freimund 1994, Yu \& Rosewell 1996, Ferro et al. 1999). Recently, Angulo-Martínez and Beguería (2009) reviewed several methods of estimating rainfall erosivity based on different data sources, showing that reasonably accurate estimations can be obtained from daily rainfall data if at least a relatively short data base of high frequency data is available.

Previous work has shown that the spatial and temporal variability of rainfall intensity can be explained by coupled modes of atmospheric circulation patterns (Hurrell 1995; Jones et al. 1997; Hurrell et al. 2003). The main atmospheric circulation pattern that affects the climate of Western Europe is the North Atlantic Oscillation, NAO (Jacobeit 1987; Moses et al. 1987). The NAO is characterized by a north-south sea level pressure dipolar pattern, with one of its centres located over Iceland and the other one approximately over the Azores Islands, (Figure 1). The positive phase of the NAO reflects below normal heights and pressure across the high latitudes of the North Atlantic, and above-normal heights and pressure over the central North Atlantic. The NAO negative mode reflects a high-pressure blocking in the northeast Atlantic and more meridional circulation than the opposite mode. Upper-air troughs and incursions of polar air over the Mediterranean are more frequent during negative NAO, and the Atlantic storm tracks are displaced southwards. All these factors are responsible for wetter conditions in the western Mediterranean (Jacobeit 1987; Moses et al. 1987; Maheras, 1988; Kutiel et al. 1996). The influence of the NAO on precipitation over the Iberian Peninsula has been recognized in many studies (Rodó et al., 1997; Esteban-Parra et al., 1998; Rodríguez-Puebla et al., 1998; Martín-Vide and Gómez, 1999; Serrano et al., 1999; Goodess and Jones, 2002; 
Lopez-Bustins et al., 2008), and is especially strong in its south-western and central areas (Martin-Vide and Lopez-Bustins, 2006).

In contrast, the Mediterranean coast of Spain is dominated by more easterly Mediterranean influences (Dünkeloh and Jacobeit, 2003; Martin-Vide and Lopez-Bustins, 2006; GonzálezHidalgo et al., 2009). In this area the pre-eminence of the NAO in explaining the variability of rainfall leads way to other circulation patterns such as the Mediterranean Oscillation, MO (Conte et al. 1989; Palutikof, 2003), and the Western Mediterranean Oscillation, WeMO (Martin-Vide and Lopez-Bustins, 2006), as several studies have revealed (Dünkeloh and Jacobeit, 2003; González-Hidalgo et al., 2009). The MO is a low-frequency variability pattern producing opposing barometric, thermal and pluviometric anomalies between the east and west extremes of the Mediterranean basin. The positive mode of MO is related to anticyclonic conditions in the western Mediterranean and a trough in the east, and with below-average rainfall rates in the entire Mediterranean basin. In its negative mode, a low pressure is located near the British Isles or north of the Iberian Peninsula while anticyclonic conditions prevail in the Mediterranean. This situation is related with rainfall events in the western part of the Mediterranean basin (Dünkeloh and Jacobeit, 2003). The Western Mediterranean Oscillation (WeMO) is defined within the synoptic framework of the western Mediterranean basin (Martín-Vide and Lopez-Bustins, 2006). The positive phase of the WeMO corresponds to the anticyclone over the Azores enclosing the southwest Iberian quadrant and low-pressures in the Liguria Gulf. This situation is related with above-average rainfall at the north and northeast of the Iberian Peninsula, especially in January when it is associated with advections from the Atlantic Ocean in the north-west. The correlation coefficient between the WeMO and monthly precipitation is 0.6 in the Bay of Biscay (Martín-Vide and Lopez-Bustins, 2006). Its negative phase coincides with central European anticyclone located north of Italy and a low-pressure centre, often cut off from northern latitudes, in the framework of the Iberian south-west. Most of the precipitations in the eastern parts of the Iberian Peninsula, especially in December, are 
associated with this situation. Its neutral phase coincides with low-pressures over the western Mediterranean basin and the surrounding areas.

Despite the well-known relationships between atmospheric teleconnection patterns and rainfall amounts, very few studies have been devoted to analyzing their influence on rainfall erosivity. In the eastern part of the Iberian Peninsula, De Luis et al. (2010) related monthly negative trends in rainfall erosivity_estimated by the modified Fournier Index (MFI Arnoldus, 1977) and the precipitation concentration index (PCI, Oliver 1980)-with the increase of the NAO during the period 1951-2000. Clarke and Rendell (2010) related the reduction in badland erosion rates in south Italy with the increase of the NAO since the 1980's. Other studies have addressed the influence of the El Niño-Southern Oscillation (ENSO) on rainfall erosivity in some areas of United States (D’Odorico et al. 2001) and Peru (Romero et al. 2007). No studies however have compared the varying influence of several teleconnection patterns on rainfall erosivity over a single region.

The aim of this study is to assess the influence of the NAO, MO and WeMO on daily rainfall erosivity at the annual and monthly scales in NE Spain, during the period 1955-2006. A second objective is to identify changes in the probability of occurrence of extreme daily erosivity events in relation with daily atmospheric circulation indices.

\section{Study area and methods}

\subsection{Study area}

The study area covers the northeast of Spain, encompassing an area of about $147,000 \mathrm{~km}^{2}$ that corresponds to the administrative territorial province demarks which conform the Ebro Basin. The study area is geographically complex, including several mountain ranges and a main central valley, the Ebro River basin. The area is limited to the north by the Cantabric Sea 
(Atlantic Ocean), the Cantabrian Range and the Pyrenees, with maximum elevations above $3000 \mathrm{~m}$ a.s.1. At the south and southwest, the Iberian Range closes the Ebro valley, with maximum elevations in the range of 2000-2300 $\mathrm{m}$ a.s.1. To the east the valley is closed by the Catalan Prelitoral Range, with maximum elevations of 1000-1900 m a.s.1., and then continues to the Mediterranean Sea, (figure 2). Mountain areas represent approximately $20 \%$ of the study area.

The climate is influenced by the Atlantic Ocean and the Mediterranean Sea, and the effect of the relief on precipitation and temperature. The bordering mountain ranges isolate the central valley, blocking the maritime influence and resulting in a continental climate with semi-arid conditions (Lana and Burgueño 1998). A climatic gradient in the NW-SE direction is notable, determined by strong Atlantic influences in the north and northwest of the area during much of the year, and the influence of the Mediterranean to the east. The mountain ranges add complexity to the climate of the region. The Pyrenees extend the Atlantic Ocean influence to the east by increasing precipitation. Precipitation in inland areas is characterized by alternating wet and dry periods as a consequence of the seasonal displacement of the polar front and its associated pressure systems, prolonged dry periods can be followed by torrential rainfall events that last for several days. Inter-annual variability in precipitation is very high, too. The most extreme precipitation events have been recorded along the Mediterranean seaside (Romero et al. 1998 Peñarrocha et al. 2002).

Rainfall erosivity reproduces to a certain point the spatial characteristics of cumulative precipitation in the study area, as revealed by analyzing station data (figure 3 ). Three different areas can be recognized, following a NW-SE gradient. The NW zone (A), influenced by the Atlantic Ocean, shows the highest monthly rainfall values and minimum rainfall erosivity; the highest erosivity is attained at the beginning of the summer, coinciding with late spring storms. The central zone (B) includes the majority of the observatories, with precipitation 
amounts that are lower than in the NW zone (although still abundant), though erosivity is greater and shows two annual peaks, one in late spring (May-June) and a second (highest) at the end of the summer (August-September). The NE zone (C) has a typical Mediterranean rainfall behavior, with maxima in spring and autumn and highest erosivity in autumn.

Due to its complex climatology as a consequence of being a meteorological border region and the contrasted relief, the Ebro Basin has a long history of social, economic and environmental damage caused by extreme rainfall events (García-Ruiz et al. 2000, Lasanta 2003, Llasat et al. 2005). The main activity in terms of surface is agriculture, representing approximately $46 \%$ of the land use. It is extended around the Ebro valley occupying a broader area close to the Mediterranean coast. During winter agricultural soils remain uncovered in most cases. Consequently, rainfall erosivity is the principal cause of soil erosion with no limiting factor at that time.

\subsection{Daily rainfall erosivity database}

For this study two databases were used (figure 2): i) 110 selected rainfall series from the Ebro river basin authority's hydrologic information system, with precipitation data at a time resolution of 15 min since $1997\left(\mathrm{P}_{\mathrm{SAIH}}\right)$; and ii) 156 daily rainfall series from the Spanish meteorological agency, with daily (0600 to 0600 hours, local time) precipitation amounts for the period 1955-2006, $\left(\mathrm{P}_{\mathrm{AEMET}}\right)$. Precipitation time series were quality controlled via a process that included reconstruction, gap filling, quality control and homogeneity testing (VicenteSerrano et al. 2009a). The SAIH dataset had the adequate time resolution for computing rainfall erosivity, but only covered eleven years. The AEMET dataset has the adequate length for undertaking climatological studies, but its coarser time resolution does not allow to directly 
compute rainfall erosivity. Therefore, we used a transformation for estimating daily erosivity values from daily rainfall amounts (Angulo-Martínez and Beguería, 2009).

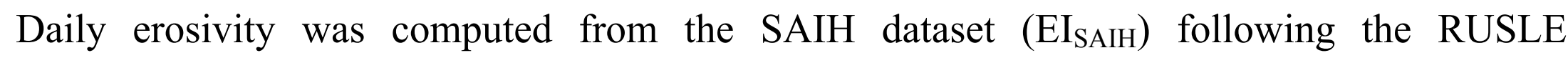
methodology (Renard et al. 1997). Daily rainfall amounts were also calculated from the SAIH dataset $\left(\mathrm{P}_{\mathrm{SAIH}}\right)$. This allowed fitting an exponential relationship between both variables (Richardson et al., 1983):

$$
E I_{m}=a_{m} P^{b_{m}}+\varepsilon, \quad m=\{1, \ldots, 12\},
$$

where $a$ and $b$ are empirical parameters and $\varepsilon$ is a random, normally distributed error. Parameters $a$ and $b$ are adjusted month-by-month $(m)$ to take seasonal variations in rainfall characteristics into account. Parameter estimation was achieved by weighted least squares (WLS) regression after a logarithmic transformation of the terms in equation (1). Weights were assigned to the observations in order to reduce the excessive influence of small erosive events during parameterization. Spatial interpolation of the parameters $a_{m}$ and $b_{m}$ by splines allowed obtaining local values of these parameters over the study area. This allowed applying equation (1) to the daily precipitation values of the AEMET dataset, to obtain a daily erosivity database for the period 1955-2006.

Annual and monthly cumulative values of the RUSLE $R$ factor were obtained by aggregating the daily $E I_{30}$ values. This allowed determining the periods of the year for which the effect of teleconnection patterns was stronger. Daily analysis was then performed focused on those periods.

\subsection{Atmospheric circulation indices}


To calculate daily indices for the atmospheric teleconnection patterns (namely NAOi, MOi and WeMOi) daily sea-level pressure grids from the ds010.0 Daily Northern Hemisphere Sea Level Pressure Grids data set (University Corporation for Atmospheric Research, 1979) were used (Figure 1). Following Jones et al. (1997), a North Atlantic Oscillation index (NAOi) was calculated as the normalized difference between time series of sea level pressure recorded at two points in the southwest Iberian Peninsula (Gibraltar, $35^{\circ} \mathrm{N} 5^{\circ} \mathrm{W}$ ) and southwest Iceland (Reykjavik, $65^{\circ} \mathrm{N}, 20^{\circ} \mathrm{W}$ ). MOi, as defined by Palutikof (2003), was calculated as the daily normalized difference between the SLP at Gibraltar $\left(35^{\circ} \mathrm{N} 5^{\circ} \mathrm{W}\right)$ and $\operatorname{Lod}\left(\right.$ Israel), $30^{\circ} \mathrm{N}, 35^{\circ} \mathrm{E}$. WeMOi was calculated as the daily normalized difference between the SLP at Gibraltar $\left(35^{\circ} \mathrm{N}\right.$ $\left.5^{\circ} \mathrm{W}\right)$ and Parma $\left(45^{\circ} \mathrm{N}, 10^{\circ} \mathrm{E}\right)$. Positive and negative events of the atmospheric circulation indices were identified as those days having values of the indices higher than 0.5 and lower than -0.5 , respectively.

\subsection{Differences in annual and monthly rainfall erosivity during negative and positive days of the atmospheric circulation patterns}

To evaluate the relationship between the atmospheric circulation indices- $\mathrm{NAO}_{\mathrm{i}}, \mathrm{MO}_{\mathrm{i}}$ and $\mathrm{WeMO}_{\mathrm{i}}$ - and rainfall erosivity we obtained for each index two time series of daily rainfall erosivity corresponding to values of the index above 0.5 and below -0.5 , respectively, (Figure 4). Therefore, we computed the relative difference $E I_{d i f}$ between median daily erosivity registered during negative days $\left(E I_{-}\right)$and positive days $\left(E I_{+}\right)$of the indices, with respect to the median of the daily erosivity registered during positive days:

$$
E I_{d i f}=\left(E I_{-}-E I_{+}\right) / E I_{+},
$$

where $E I_{-}$and $E I_{+}$are the median daily rainfall erosivity during negative and positive days of a given atmospheric circulation index- $\mathrm{NAO}_{\mathrm{i}}, \mathrm{MO}_{\mathrm{i}}$ and $\mathrm{WeMO}-$, as defined above. For 
example, $(150-100) / 100=0.5$ means that erosivity was $50 \%$ higher during negative days than during positive days, while $(100-150) / 150 \quad 150-100=-0.33$ means that erosivity was $33.3 \%$ lower during negative days than during positive days. The statistical significance of the relative differences was evaluated using the Wilcoxon-Mann-Whitney (WMW) rank test (Siegel and Castelan, 1988). The nonparametric WMW test-based on the median-was preferred due to its robustness against non-normality of the variables (Helsel and Hirsch, 1992). The significance level was established at $\alpha=0.05$. Maps of $E I_{d i f}$ for the whole period and month by month were produced to help visualize spatial differences in the effect of atmospheric circulation indices on daily rainfall erosivity.

\subsection{Extreme value analysis of rainfall erosivity during positive and negative days of the atmospheric circulation patterns}

Changes in the probability distributions of extreme daily rainfall erosivity depending on the NAO, MO and WeMO phase were analyzed using the extreme value theory (Hershfield, 1973). Peaks-over-threshold (POT) series of daily rainfall erosivity were obtained for positive and negative NAO, MO and WeMO days, by selecting only those observations exceeding a threshold value $u$ corresponding to the 90 th percentile of the series. The resulting series were fitted to a Generalized Pareto (GP) distribution by the maximum likelihood approach. GP is the limit distribution of a POT variable, proving that the POT occurrences fit a Poisson process, i.e. that the occurrences are time independent. The appropriateness of the GP distribution to model the daily erosivity POT series was checked by means of the L-moment ratios diagram and by a Kolmogorov-Smirnov test (Beguería 2005; Beguería et al. 2009). The 
GP distribution is described by a shape parameter $k$ and a scale parameter $\alpha$, with probability density function:

$$
f(x)=\frac{1}{\alpha}\left[1-\frac{k}{\alpha}(x-\varepsilon)\right],
$$

and distribution function:

$$
P(X \leq x)=1-\left(1-\kappa \frac{(x-\varepsilon)}{\alpha}\right)^{\frac{1}{\kappa}}
$$

where $x$ is the daily rainfall erosivity exceeding the threshold value $u$, which acts as a location parameter. The highest expected rainfall erosivity $X_{T}$ over a period of $T$ years is obtained as:

$$
X_{T}=\varepsilon+\frac{\alpha}{\kappa}\left[1-\left(\frac{1}{\lambda T}\right)^{\kappa}\right],
$$

where $\lambda$ is the average number of events per year.

Maps of the extreme daily rainfall erosivity events corresponding to a return period of 10 years were produced for positive and negative NAO, MO and WeMO days based on equation (5). These maps were compared in order to evaluate differences in the expected extreme events depending on each circulation pattern. The POT analysis was applied to the period between September to April, during which the influence of circulation patterns was highest, as was determined by the previous analysis.

\section{Results}

3.1 Annual and monthly differences in median daily rainfall erosivity during negative and positive NAO, MO and WeMO days 
The results of the WMW test comparing the daily distributions of rainfall erosivity during positive and negative NAO, MO and WeMO days yielded 154 (99\%), 149 (96\%) and 144 (92\%) significant differences, respectively (Table 1). Differences were found in almost all months, although they where especially important between September and April. Most observatories reflected this behaviour. During summer (June to August) the influence of the circulation patterns was less evident.

Relative differences in rainfall erosivity during negative and positive days of the circulation patterns varied significantly between teleconnection indices (Figure 5). Median rainfall erosivity was only moderately ( 1 to 3 times) higher during negative NAO days. The Mediterranean indices, in contrast, had a stronger influence. Thus, in the lower Ebro valley to the SE of the area the median erosivity was between 3 and 10 times higher during negative days of $\mathrm{MO}_{\mathrm{i}}$ and between 10 and 15 times higher during negative days of $\mathrm{WeMO}_{\mathrm{i}}$. For these two teleconnection indices two areas were found-in the north in the case of $\mathrm{MO}_{\mathrm{i}}$ and in the north-northwest in the case of $\mathrm{WeMO}_{\mathrm{i}}-$ where the influence of these teleconnection patterns was reversed, i.e. erosivity was higher during positive days. This relationship, however, was not significant according to the WMW test.

At the monthly basis, the strongest differences occurred between September and April (Figures 6 to 8). In general, daily rainfall erosivities in the eastern area responded most to the synoptic situations related to negative conditions of the atmospheric circulation indices. This area corresponds to the region described in Figure 3C, where the highest rainfall erosivities are associated to intense rainfall events in autumn and early winter.

At the monthly scale, the NAO influence (Figure 6) was significant from October to February in most of the study area, and in April-May in some areas. From June to September the influence of the NAO on rainfall erosivity was not significant. The strongest influence of NAO was found close to the Mediterranean coast, especially in the upper north-east 
Mediterranean area. The strongest differences between positive and negative NAO days were found in November, with erosivity values up to 30 times higher during negative conditions. Again, this influence was higher in the SE of the study area. Other months (January, April, May) showed also significant influences in some areas, but much more spatially localized.

The MO revealed a stronger influence than NAO, especially between September and March (Figure 7). This influence was strongest along the Mediterranean coast, and was extended towards inland depending on the month. The strongest relative difference between positive and negative days was registered in December, for which most of the NE region had daily rainfall erosivity values 30 times greater on negative compared to positive days. The strongest relative differences, however, were linked to the WeMO (Figure 8). Rainfall erosivity under negative WeMO days was up to 130 times greater than under positive days, concentrated along the Mediterranean coast between October and January. The influence of the WeMO was restricted spatially to a narrower area closer to the coast, only extending to the centre of the study area during some months.

\subsection{Differences in extreme rainfall erosivity between negative and positive NAO, MO and WeMO days}

The POT series of rainfall erosivity had a good fit to the GP distribution, as shown by the Lmoment diagrams (Figure 9). Independently of the sign of the atmospheric circulation indices, the empirical L-moments of rainfall erosivity series plotted close to the theoretical curve of the GP distribution. This was especially evident when other possible candidate distributions were compared. The Kolmogorov-Smirnov test allowed accepting the GP distribution for the data, since only in very few cases the null hypothesis that the data came from a GP distribution was rejected at the defined significance level. This result agrees with recent studies demonstrating 
the strong performance of the GP distribution in fitting extreme hydrological variables using partial duration series (Hosking and Wallis, 1987; Madsen and Rosbjerg, 1997; Beguería, 2005). Here we also found that the GP distribution has a good performance in fitting daily rainfall erosivity data.

By adjusting the daily rainfall erosivity series for the selected months to the GP probability distribution we obtained the probability of occurrence of extreme daily rainfall erosivity records associated with negative and positive NAO, MO and WeMO. Results showed highest rainfall erosivity values were expected under negative NAO, MO and WeMO conditions in most of the regions. Of the three indices, the highest values were expected under negative WeMO. Differences could be found also between observatories. Those located inland to the south and south-west of the region did not show significant differences, coinciding with the results obtained in the precedent section. The Mediterranean coast and the mountains in the north and south of the area showed a high contrast between negative and positive conditions.

The rainfall erosivity expected for a return period of 10 years related with negative and positive NAO, MO and WeMO during winter are shown in Figure 10. Under negative NAO, daily rainfall erosivity values of $50 \pm 8$ up to $385 \pm 22 \mathrm{MJ} \mathrm{mm} \mathrm{ha}^{-1} \mathrm{~h}^{-1} \mathrm{~d}^{-1}$ can be expected in the northern and eastern parts of the region. The highest values were concentrated in the northeast perimeter, close to the Mediterranean coast from the Ebro Delta upwards to the north and in the Central Pyrenees. Under positive NAO most of the region showed low expected daily rainfall erosivity values ranging between $5 \pm 0.5$ and $50 \pm 8 \mathrm{MJ} \mathrm{mm} \mathrm{ha}^{-1} \mathrm{~h}^{-1} \mathrm{~d}^{-1}$. High erosivity values during positive NAO were only expected in localized areas such as in the Ebro Delta and in the Central Pyrenees. Under negative MO the spatial pattern of the high daily rainfall erosivity values was similar to negative NAO, though higher values were expected. Most of the Mediterranean coast could record daily rainfall erosivity values ranging between $150 \pm 12$ and $250 \pm 16 \mathrm{MJ} \mathrm{mm} \mathrm{ha}^{-1} \mathrm{~h}^{-1} \mathrm{~d}^{-1}$ with the Ebro Delta reaching values of $385 \pm 20 \mathrm{MJ} \mathrm{mm} \mathrm{ha}^{-1} \mathrm{~h}^{-1}$ 
$\mathrm{d}^{-1}$. In contrast, under positive MO high erosivity values were only expected in a localized area in the north of the region, with expected values ranging between 100 and $125 \mathrm{MJ} \mathrm{mm} \mathrm{ha}^{-1} \mathrm{~h}^{-1}$ $\mathrm{d}^{-1}$. Under negative WeMO, the previous spatial patterns were reproduced but expected values were higher than for the other atmospheric patterns. A broader area close to the Mediterranean coast and in the central Pyrenees expected daily rainfall erosivity values ranging between $150 \pm 8$ and $250 \pm 16 \mathrm{MJ} \mathrm{mm} \mathrm{ha}^{-1} \mathrm{~h}^{-1} \mathrm{~d}^{-1}$, the highest values reaching up to $500 \pm 16 \mathrm{MJ} \mathrm{mm} \mathrm{ha}^{-1}$ $\mathrm{h}^{-1} \mathrm{~d}^{-1}$ close to the Ebro Delta and extending to the north. Positive WeMO were related with high daily rainfall erosivity values in the mountain areas of north-west and in the central Pyrenees, with values ranging between $100 \pm 4$ to $150 \pm 8 \mathrm{MJ} \mathrm{mm} \mathrm{ha}^{-1} \mathrm{~h}^{-1} \mathrm{~d}^{-1}$ reaching in localised zones $250 \pm 12 \mathrm{MJ} \mathrm{mm} \mathrm{ha}^{-1} \mathrm{~h}^{-1} \mathrm{~d}^{-1}$.

Taking as example the observatory X9987 in the Ebro delta we have generated the return period curves of the winter (October-March) extreme daily rainfall erosivity under positive and negative days of the indices (Figure 11). As expected from the location of the observatory in the area for which the influence of the indices is highest, the return period curves show a high contrast between the positive and negative days of the teleconnections, especially for MO and WeMO. For example, for a return period of 50 years the expected values under negative NAO are around $1500 \mathrm{MJ} \mathrm{mm} \mathrm{ha}{ }^{-1} \mathrm{~h}^{-1} \mathrm{~d}^{-1}$, whereas under negative MO and WeMO they are higher than $3000 \mathrm{MJ} m \mathrm{ma}^{-1} \mathrm{~h}^{-1} \mathrm{~d}^{-1}$. The daily rainfall erosivity values expected under positive conditions of all of the indices are lower, especially in the case of the MO. For a return period of 50 years and positive NAO and WeMO the expected daily rainfall erosivity values are around $1000 \mathrm{MJ} \mathrm{mm} \mathrm{ha} \mathrm{h}^{-1} \mathrm{~h}^{-1}$, whereas under MO they are around $500 \mathrm{MJ} \mathrm{mm}$ $\mathrm{ha}^{-1} \mathrm{~h}^{-1} \mathrm{~d}^{-1}$.

\section{Discussion}


There is a general interest regarding the effects of climate dynamics, especially in a context of climate change, in the environment. However, very few studies have related the atmospheric circulation patterns to rainfall erosivity, due mostly to the lack of accurate rainfall erosivity series long enough to make this analysis possible. In this paper we investigate the differences in rainfall erosivity between positive and negative days of three well known atmospheric teleconnection patterns affecting precipitation in the Iberian peninsula: the NAO, the MO and the WeMO.

We analysed daily rainfall erosivity under positive and negative days of NAO, MO, and WeMO at the annual and monthly scales for the period 1955-2006 in 156 observatories in northeast Spain. The three teleconnection patterns had an influence on rainfall erosivity, with higher erosivities during negative modes of the three indices. This relationship was strongest between September and April, and almost no significance was found for summer months. Of the three indices, NAO had the weakest influence on rainfall erosivity while for MO and especially the WeMO the differences between positive and negative modes were larger. This result is in agreement with previous studies, since the negative modes of the three teleconnections are related to increasing precipitation in the study area (Conte et al. 1989; Rodríguez-Puebla et al., 1998; Palutikof, 2003; Dünkeloh and Jacobeit, 2003; Martin-Vide and Lopez-Bustins, 2006; González-Hidalgo et al., 2009). It has also been shown that WeMO has the strongest influence of the three indices, most notably during autumn and winter, when the teleconnections control the geographic location of the major atmospheric features controlling the weather over the Iberian Peninsula.

Spatially, the influence was strongest along the Mediterranean coast and decreased progressively towards the NW. The highest rainfall erosivities in the study area corresponded to negative WeMO days, and occurred around the Ebro delta. Regarding the spatial extent of the influence, the MO had the broadest extension of the significant area, while the effect of the 
WeMO was more restricted to the coastal zone. This also coincides with previous results analysing the influence of teleconnection indices on extreme rainfall events in the NE of Iberia (González-Hidalgo et al., 2009).

The results regarding the extreme events analysis were similar. Comparison of high quantile (Q90) expected values showed daily rainfall erosivity values expected for negative modes were highest for the three teleconnection patterns. The largest differences occurred along the Meditarranean coast, and WeMO showed the greatest influence between the indices. VicenteSerrano et al. (2009) analysed extreme precipitation events in the same study area based on extreme events analysis, and found that both the Mediterranean (to the east) and the Cantabrian (to the north-west) coasts experienced the strongest events, which were linked in both cases to the negative WeMO mode. This contrasts with our results, because we only found a significant relationship in the Mediterranean, but not in the NW area. This can be explained by the transformation of daily precipitation into erosivity, since the values of the parameters in equation (1) differed notably between the two regions. Especially for certain months of the year, the same amounts of daily rainfall imply much higher erosivity values in the east than in the NW, with rainfall events of Mediterranean origin tending to be more intense and concentrated (and hence, more erosive) than frontal events of Atlantic origin.

It is a well-known fact that the NAO is responsible for most of the climatic variability in the North Atlantic, especially during winter. During its negative mode cyclones move southward increasing precipitation in most of the Iberian Peninsula. This influence, however, is reduced towards the east of the region due to the effect of the complex Iberian orography, which hampers the arrival of precipitation fronts from the Atlantic. Thus, precipitation variability close to the Mediterranean coast is more controlled by Mediterranean atmospheric dynamics. In this area, coupled modes such as the MO and the WeMO have a larger influence on rainfall variability. The MO comprises those parts of the NAO linked with Mediterranean 
precipitation variability, and both indices are well correlated at the daily scale between September and April-Pearson correlation coefficient of 0.5 for daily values from $01 / 01 / 1955$ up to $31 / 12 / 2006$. The WeMO index, in contrast, is mostly uncorrelated with both indicesPearson correlation coefficient of 0.1 with $\mathrm{NAO}$, and 0.3 with $\mathrm{MO}-$. Thus, it is possible that the combined effect of negative days of NAO and of WeMO, or MO and WeMO, occurring simultaneously would result in even higher rainfall erosivity values. However, the analysis of this article is restricted to the single effect of the indices, so this possibility has not been tested.

\section{Conclusions.}

Expected rainfall erosivities can be two orders of magnitude higher under negative phases of the NAO, MO and WeMO in our study area, especially along the Mediterranean coast in autumn and early winter. The loss of fertile soil during this period of the year, when agricultural lands are mostly bare, is directly related to the rainfall erosivity and the slope gradient. Soil protection measures such as mulching help absorbing part of the kinetic energy of the rain and can be effective in reducing soil splash detachment.

\section{Acknowledgements}

We thank the Spanish Meteorological Agency (Agencia Española de Meteorología, AEMET) and the Ebro Basin Water Authority (Confederación Hidrográfica del Ebro, CHE) for providing the data used in this study. This work has been supported by the research projects CGL2008-00831/BTE, and CGL2008-01189/BTE, funded by the Spanish Ministry of Science and Innovation (CICYT). Research of M. A.-M. is supported by a JAE-Predoc Research Grant from the Spanish National Research Council (Consejo Superior de Investigaciones Científicas-CSIC). 


\section{References}

Angulo-Martínez, M., Beguería, S., 2009. Estimating rainfall erosivity from daily precipitation records: A comparison among methods using data from the Ebro Basin (NE Spain). J. Hydrol., $379,111-121$.

Angulo-Martínez, M., López-Vicente, M., Vicente-Serrano, S.M., Beguería, S., 2009. Mapping rainfall erosivity at a regional scale: a comparison of interpolation methods in the Ebro Basin (NE Spain). Hydrol. Earth. Syst. Sc., 13, 1907-1920.

Arnoldus, H.M.J., 1977. Methodology used to determine the maximum potential average annual soil loss due to sheet and rill erosion in Morocco. FAO Soils Bull., 34: 39-51

Bagarello, V., D’Asaro, F., 1994. Estimating single storm erosion index. T. ASAE, 37(3), 785791.

Banasik, K., Górski, D., 1994. Rainfall erosivity for south-east Poland. Conserving soil resources. European perspectives (ed. Rickson), 201-207. Lectures in soil erosion control, Silsoe College, Cranfield University, UK.

Beguería, S. 2005. Uncertainties in partial duration series modelling of extremes related to the choice of the threshold value, J. Hydrol., 303, 215-230.

Beguería, S., Vicente-Serrano, S.M., López-Moreno, J.I., García-Ruiz, J.M. 2009. Annual and seasonal mapping of peak intensity, magnitude and duration of extreme precipitation events across a climatic gradient, North-east Iberian Peninsula, Int. J. Climatol., 29, 1759-1779.

Brown, L.C., Foster, G.R., 1987. Storm erosivity using idealized intensity distributions. T. ASAE., 30: 379-386. 
Capolongo, D., Diodato, N., Mannaerts, C.M., Piccarreta, M., Strobl, R.O. 2008. Analyzing temporal changes in climate erosivity using a simplified rainfall erosivity model in Basilicata, southern Italy. J. Hydrol. 356, 119- 130.

Clarke, M.L.; Rendell, H.M. 2010. Climate-driven decrease in erosion in extant Mediterranean badlands. Earth Surf Proc Land. 35, 1281-1288. Doi: 10.1002/esp.1967

Conte M, Giuffrida S, Tedesco S. 1989. The Mediterranean oscillation: impact on precipitation and hydrology in Italy. Proceedings of the Conference on Climate and Water, Vol. 1. Publications of Academy of Finland: Helsinki; 121-137.

Coutinho, M.A.; Tomás, P.P. 1995. Characterization of raindrop size distributions at the Vale Formoso Experimental Erosion Centre. Catena, 25. 187-197.

De Luis, M.; González-Hidalgo, J.C.; Longares, L.A. 2010: Is rainfall erosivity increasing in the Mediterranean Iberian Peninsula? Land Degrad Dev, 21, 139-144. Doi: 10.1002/ldr.918

D’Odorico, P.; Yoo, J.; Over, T.M. 2001. An assessment of ENSO-Induced patterns of rainfall erosivity in the Southwestern United States. J. Climate, 14, 4230-4242

Dünkeloh, A.; Jacobeit, J. 2003: Circulation dynamics of Mediterranean precipitation variability 1948-98. Int. J. Climatol., 23, 1843-1866. Doi: 10.1002/joc.973

EEA, 2000. CORINE land cover 2000. European Environment Agency. $<$ http://image2000.jrc.it>.

Esteban-Parra MJ, Rodrigo FS, Castro-Diez Y. 1998. Spatial and temporal patterns of precipitation in Spain for the period 1880-1992. Int. J. Climatol.18: 1557-1574.

Ferro, V., Porto, P., Yu, B. 1999. A comparative study of rainfall erosivity estimation for southern Italy and southeastern Australia, Hydrolog sci. j., 44, 3-24. 
García-Ruiz, J.M., Arnáez, J., White, S.M., Lorente, A., Beguería, S. 2000. Uncertainty assessment in the predition of extreme rainfall events: an example from the Central Spanish Pyrenees. Hydrol. Process., 14: 887-898.

González-Hidalgo, J.C.; Lopez-Bustins, J.A.; Štepánek, P.; Martín-Vide, J.; De Luis, M. 2009: Monthly precipitation trends on the Mediterranean fringe of the Iberian peninsula during the second-half of the twentieth century (1951-2000). Int. J. Climatol., 29, 1415-1429. Doi: $10.1002 /$ joc. 1780

Goodess, C.M., Jones, P.D. 2002. Links between circulation and changes in the characteristics of Iberian rainfall. Int. J. Climatol. 22: 1593-1615.

Helsel, D.R., Hirsch, R.M. 1992. Statistical methods in water resources. 522pp., Elesevier, New York.

Hershfield, D. M. (1973), On the probability of extreme rainfall events, BAM Meteorol. Soc., $54,1013-1018$.

Hosking, J. R. M., and J. R. Wallis (1987), Parameter and quantile estimation for the Generalized Pareto distribution, Technometrics, 29, 339- 349.

Hurrell, J. 1995. Decadal trends in North Atlantic Oscillation and relationship to regional temperature and precipitation. Science. $269,676-679$.

Hurrell, J., Kushnir, Y., Ottersen, G., Visbeck, M. (Eds). 2003. The North Atlantic Oscillation: climate significance and environmental impacts. Geophys. Monogr. Ser., vol 134, AGU, Washinton, D.C.

Jacobeit J. 1987. Variations of trough positions and precipitation patterns in the Mediterranean area. Int. J. Climatol.7: 453-476. 
Jones, P.D., Jónsson, T., Wheeler, D. 1997. Extension to the North Atlantic Oscillation using early instrumental pressure observations from Gibraltar and South-West Iceland. Int. J. Climatol., 17, 1433-1450.

Kutiel H, Maheras P, Guika S. 1996. Circulation indices over the Mediterranean and Europe and their relationship with rainfall conditions across the Mediterranean. Theor. Appl. Climatol. 54: 125-138.

Lana X, Burgueño A. 1998. Spatial and temporal characterization of annual extreme droughts in Catalonia (Northeast Spain). Int. J. Climatol.18: 93-110.

Lasanta, T. 2003. Gestión agrícola y erosión del suelo en la cuenca del Ebro: el estado de la cuestión. Zubía, 21: 76-96.

Llasat, M.C., Barriendos, M., Barrera, A., Rigo, T. 2005. Floods in Catalonia (NE Spain) since the 14th century. In Benito, G, Ouarda, T.B.M.J., Bárdossy, A (Eds.) Palaeofloods, hystorical data \& climate variability: Applications in flood risk assessment. J. Hydrol., 313 (1-2): 32-47.

Lopez-Bustins, J.A.; Martin-Vide, J.; Sanchez-Lorenzo, A. 2008. Iberia winter rainfall trends based upon changes in teleconnection and circulation patterns. Global Planet Change. 63, 171176. Doi:10.1016/j.gloplacha.2007.09.002

Madsen, H., and D. Rosbjerg (1997), The partial duration series method in regional indexflood modeling, Water Resour Res, 33, 737 - 746.

Maheras P. 1988. Changes in precipitation conditions in the western Mediterranean over the last century. Int. J. Climatol., 8, 179-189.

Martín-Vide, J.; Lopez-Bustins, J.A. 2006. The Western Mediterranean Oscillation and rainfall in the Iberian Peninsula. Int. J. Climatol. 26, 1455-1475. Doi: 10.1002/joc.1388 
Martin-Vide J, Gomez L. 1999. Regionalization of peninsular Spain based on the length of dry spells. Int. J. Climatol., 19, 537-555.

Moses T, Kiladis GN, Diaz HF, Barry RG. 1987. Characteristics and frequency of reversals in mean sea level pressure in the North Atlantic sector and their relationship to long-term temperature trends. Int. J. Climatol., 7, 13-30.

Oliver, J. E. 1980. Monthly precipitation distribution: a comparative index, Prof. Geogr., 32, $300-309$.

Palutikof JP. 2003. Analysis of Mediterranean climate data: measured and modelled. In Mediterranean Climate-Variability and Trends, Bolle HJ (ed.). Springer-Verlag: Berlin; 133153.

Peñarrocha, D, Estrela, MJ, Millán M. 2002. Classification of daily rainfall patterns in a Mediterranean area with extreme intensity levels: the Valencia region. Int. J. Climatol. 22: $677-695$.

Petkovsek, G., Mikos, M. 2004. Estimating the R factor from daily rainfall data in the subMediterranean climate of southwest Slovenia. Hydrolog. sci. j., 49 (5): 869-877.

Renard, K.G., Foster, G.R., Weesies, G.A., McCool, D.K., Yoder, D.C., 1997. Predicting Soil Erosion by Water: A Guide to Conservation Planning with the Revised Universal Soil Loss Equation (RUSLE). Handbook \#703. US Department of Agriculture, Washington, DC.

Renard, K.G., Freimund, J.R., 1994. Using monthly precipitation data to estimate the R factor in the revised USLE. J. hydrol., 157 (1-4): 287-306.

Richardson, C.W., Foster, G.R., Wright, D.A., 1983. Estimation of Erosion Index from Daily Rainfall Amount. T. ASAE, 26, 153-160. 
Rodó X, Baert E, Comin FA., 1997. Variations in seasonal rainfall in southern Europe during the present century: relationships with the North Atlantic oscillation and the El Niño-Southern oscillation. Clim. Dynam. 19: 275-284.

Rodriguez-Puebla C, Encinas AH, Nieto S, Garmenia J. 1998. Spatial and temporal patterns of annual precipitation variability over the Iberian Peninsula. Int. J. Climatol. 18: 299-316

Romero, C.C., Baigorría, G.A., Stroosnijder, L. 2007. Changes of erosive rainfall for El Niño and La Niña years in Northern Andean highlands of Peru. Climatic Change. 85, 343-356.

Romero, R., Guijarro, J.A., Ramis, C. and Alonso, S. 1998. A 30-year (1964-1993) daily rainfall data base for the Spanish Mediterranean regions: first exploratory study. Int. J. Climatol., 18: 541-560

Serrano, A., J. A. García, V. L. Mateos, M. L. Cancillo, and J. Garrido, 1999: Monthly modes of variation of precipitation over the Iberian Peninsula. J. Climate, 12, 2894-2919.

Siegel, S., Castelan, N.J. 1988. Nonparametric statistics for the behavioral sciences. McGrawHill, New York.

University Corporation for Atmospheric Research (1979), Daily Northern Hemisphere sea level pressure grids, continuing from 1899, ds010.0, CISL Data Support Sect., Natl. Cent. for Atmos. Res., Boulder, Colo., (Updated monthly.).

Van Dijk, A.I.J.M., Bruijnzeel, L.A., Rosewell, C.J. 2002. Rainfall intensity -kinetic energy relationships: a critical literature appraisal. J. Hydrol., 261, 1-23.

Vicente-Serrano, S.M., Beguería, S., López-Moreno, J.I., García-Vera, M.A., Stepanek, P. 2009a. A complete daily precipitation database for north-east Spain: Reconstruction, quality control and homogeneity. Int. J. Climatol., DOI: 10.1002/joc.1850 
Vicente-Serrano S.M., Beguería, S., López-Moreno, J.I., El Kenawy, A. \& Angulo, M. 2009. Daily atmospheric circulation events and extreme precipitation risk in Northeast Spain: the role of the North Atlantic Oscillation, Western Mediterranean Oscillation, and Mediterranean Oscillation. J. Geophys. Res-Atmos. 114, D08106, Doi: 10.1029/2008JD011492.

Wischmeier, W.H., 1959. A rainfall erosion index for a universal soil-loss equation. Soil Sci Soc of Am Pro, 23: 246-249.

Wischmeier, W.H., Smith, D.D., 1978. Predicting rainfall erosion losses: a guide to conservation planning. USDA Handbook 537, Washington, DC.

Yin, S., Xie, Y., Nearing, M.A., Wang, C. 2007. Estimation of rainfall erosivity using 5- to 60-minute fixed-interval rainfall data from China. Catena 70, 3: 306-312.

Yu, B., Rosewell, C.J., 1996. Rainfall erosivity estimation using daily rainfall amounts for South Australia. Aust. J. Soil Res., 34, 721-733 
Figure Captions

Figure 1. Sea-level pressure points used to calculate the daily atmospheric indices. The black coloured indicates the study area.

Figure 2. Digital Terrain Model of the study area showing the spatial distribution of the

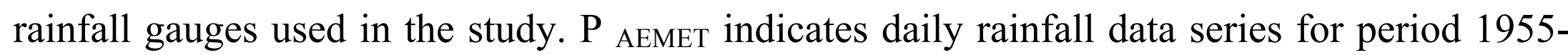
2006 provided by the Spanish Meteorological Agency. $\mathrm{P}_{\mathrm{SAIH}}$ indicates the $15^{\prime}$ rainfall data series for period 1997-2006 provided by the Automatic Hydrologic Information System of the Ebro river basin.

Figure 3. Homogeneous monthly rainfall erosivity regions in NE Spain (EI index, see methods section), and precipitation associated obtained by means of hierarchical cluster. Grey area indicate agricultural land $\left(68,000 \mathrm{~km}^{2}\right.$ - from Corine Land Cover version 8/2005 (EEA, 2000)).

Figure 4. Daily time series of NAOi, WeMOi, MOi and rainfall erosivity for the observatory X9987 (Ebro Delta) between 01/01/2001 and 31/03/2001. Red and blue regions indicate positive and negative phases according to the three teleconnection indices, which were used to construct time series of daily rainfall erosivity.

Figure 5. Relative differences in median daily rainfall erosivity at annual scale during negative and positive days of the atmospheric circulation indices. Masked areas indicate no significant difference.

Figure 6. Relative differences in median daily rainfall erosivity month by month during negative and positive NAO days. Masked areas indicate no significant difference.

Figure 7. Relative differences in median daily rainfall erosivity month by month during negative and positive MO days. Masked areas indicate no significant difference. 
Figure 8. Relative differences in median daily rainfall erosivity month by month during negative and positive WeMO days. Masked areas indicate no significant difference.

Figure 9. L-moments ratio diagram, comparing empirical L-moment ratios (L-skewness and L-kurtosis) with the ones of several widely used extreme value distributions: Generalized Extreme Value (GEV), Log-Normal (LN), Pearson III (PIII) and Pareto (GP).

Figure 10. Expected extreme daily rainfall erosivity during winter (September-April) corresponding to a return period of 10 years under negative and positive days of the atmospheric circulation indices.

Figure 11. Return period curves for Ebro river delta (observatory X9987) of the winter (September-April) extreme daily rainfall erosivity under positive and negative days of the indices analysed. Grey line represents the extreme daily rainfall erosivity values under the different days of the indices for a return period of $10 \mathrm{y}$, cartographied for all the observatories in figure 10 . 
$20^{\circ} 0^{\prime} 0 " \mathrm{~W}$

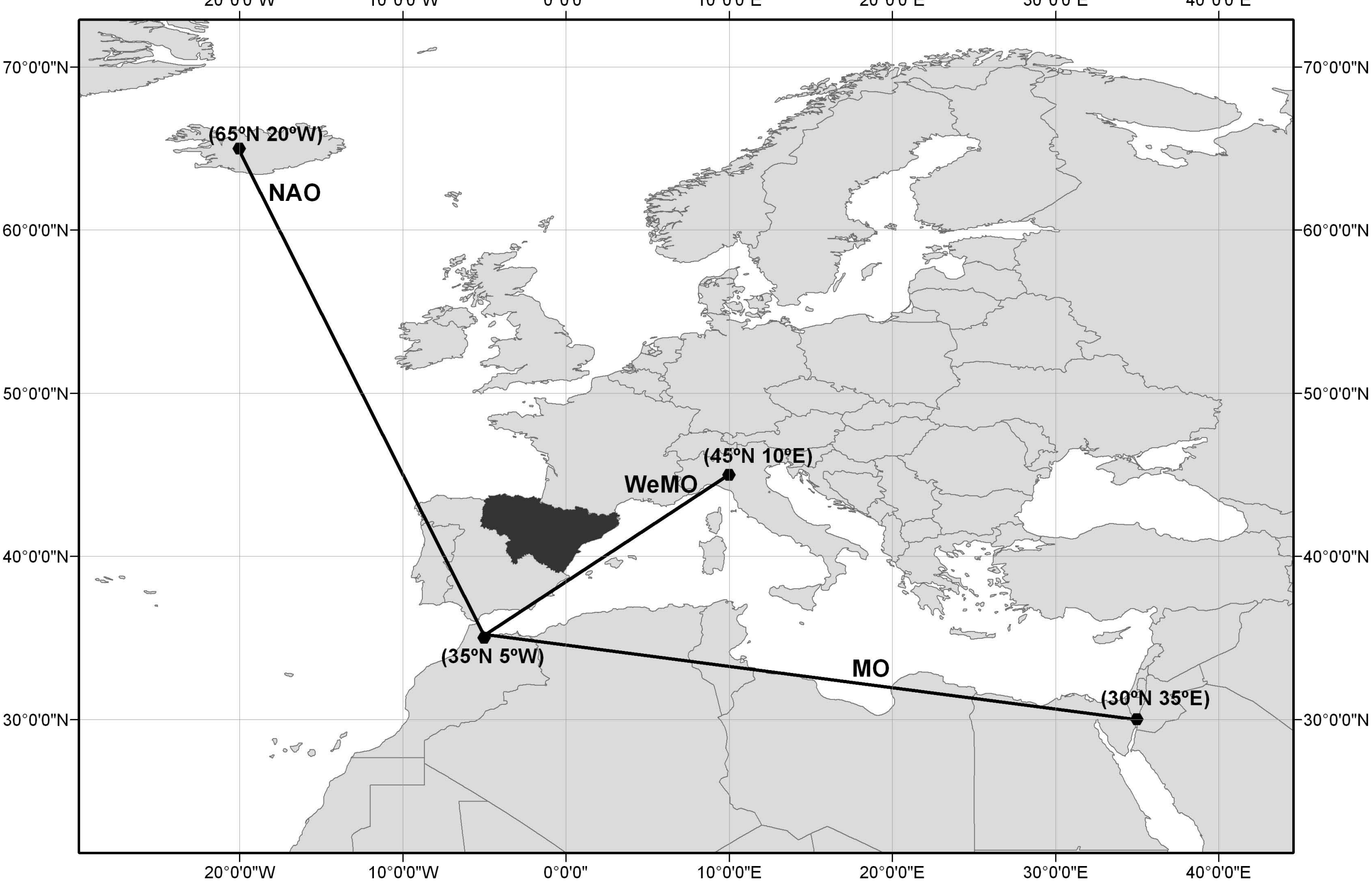




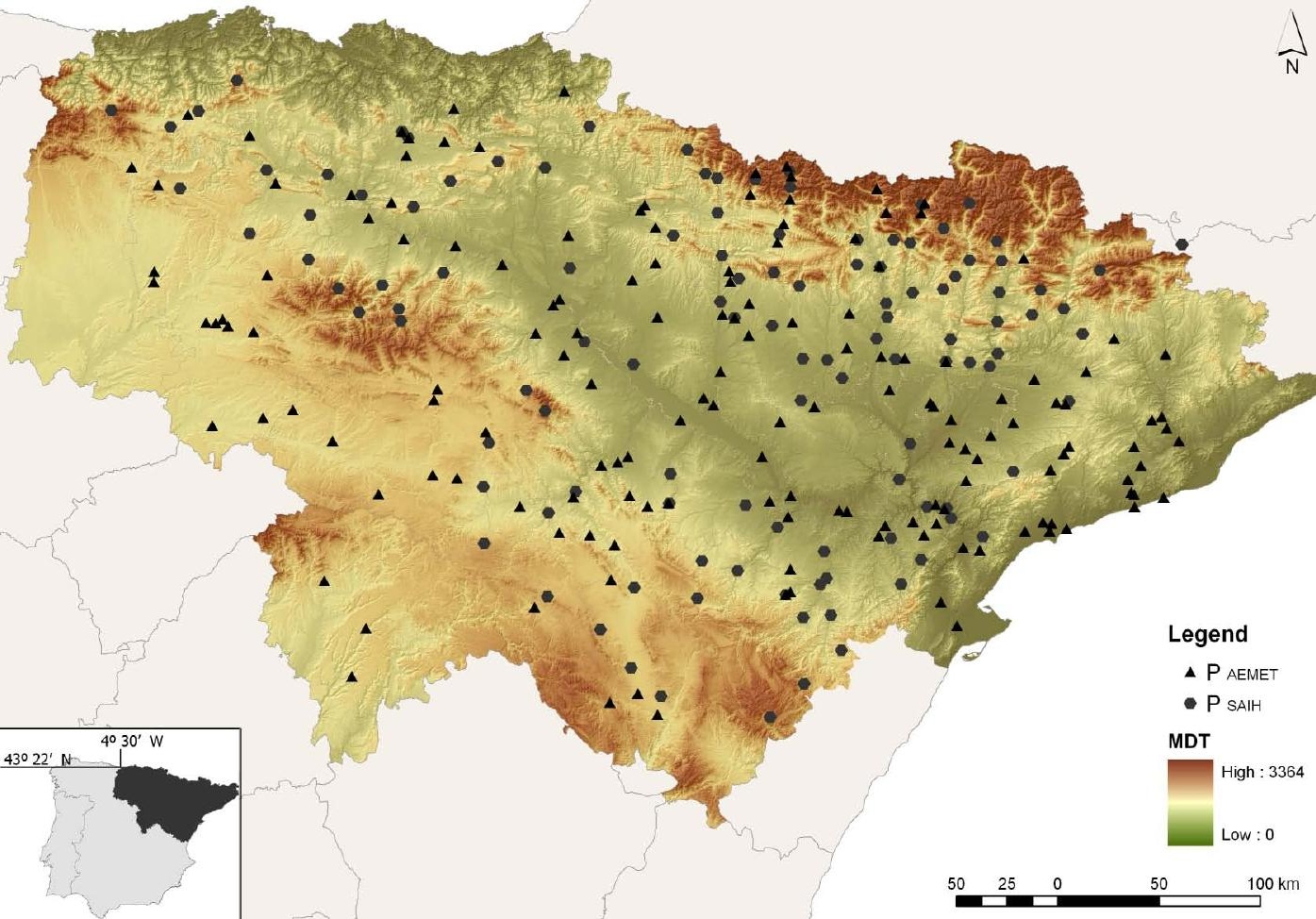




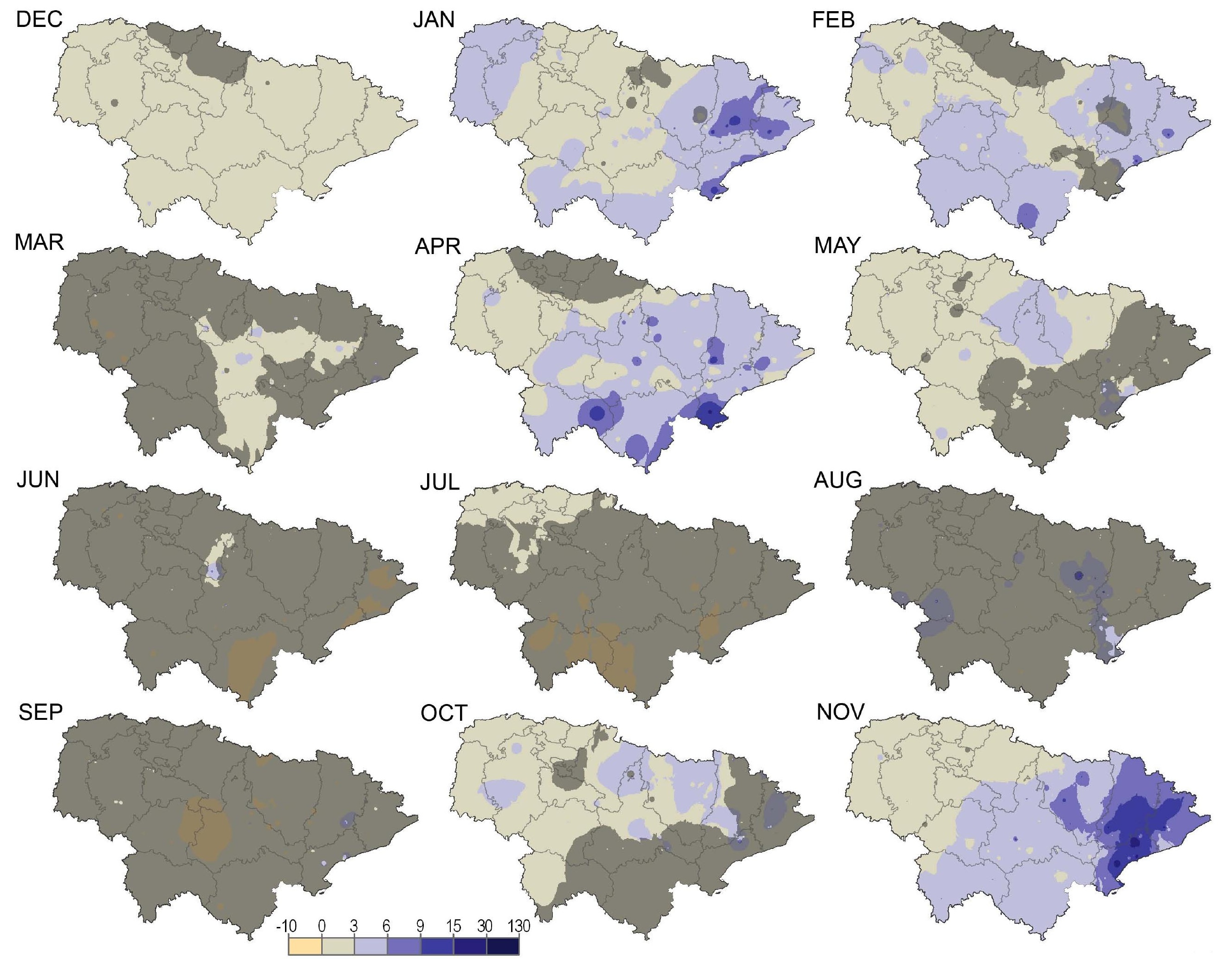




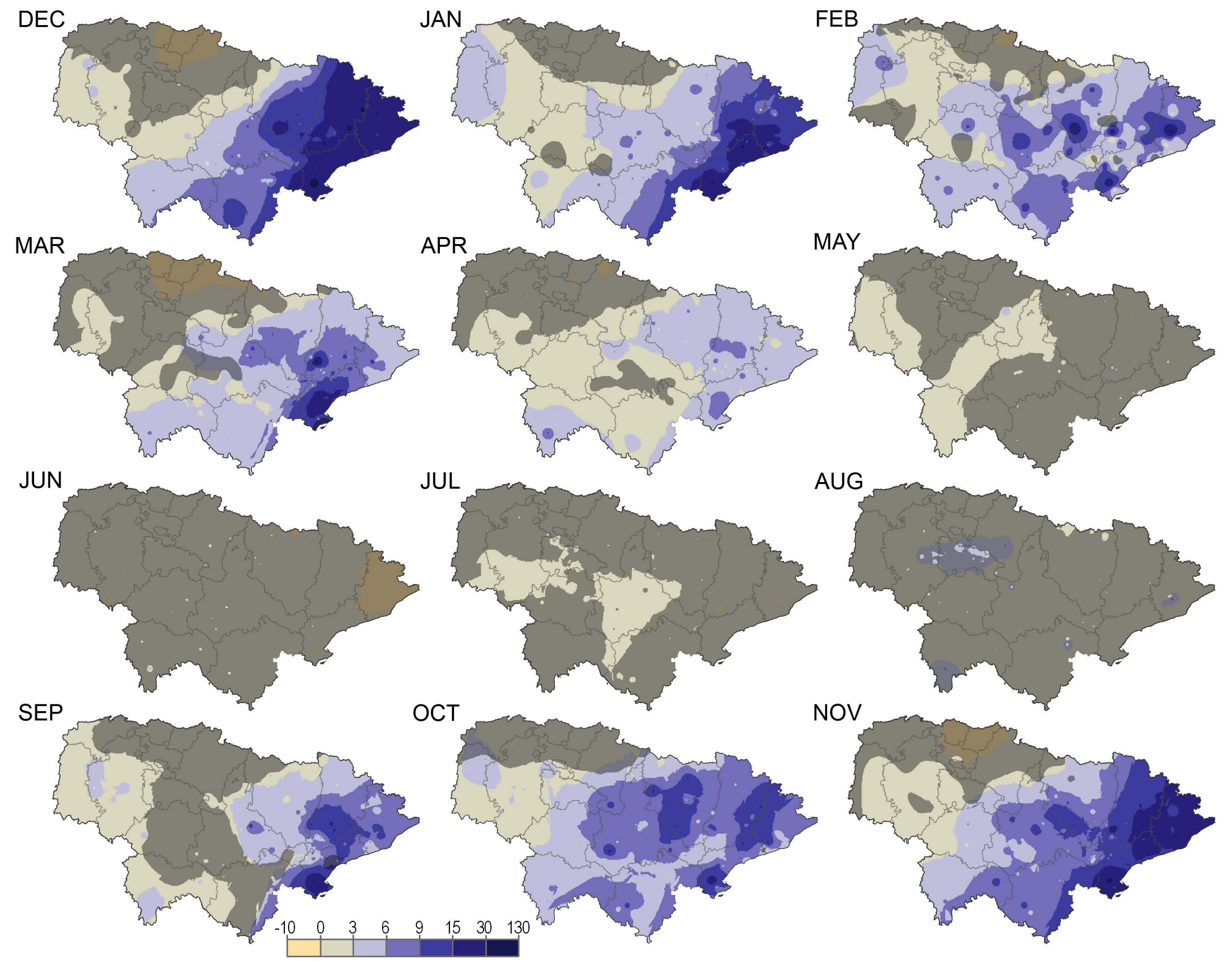




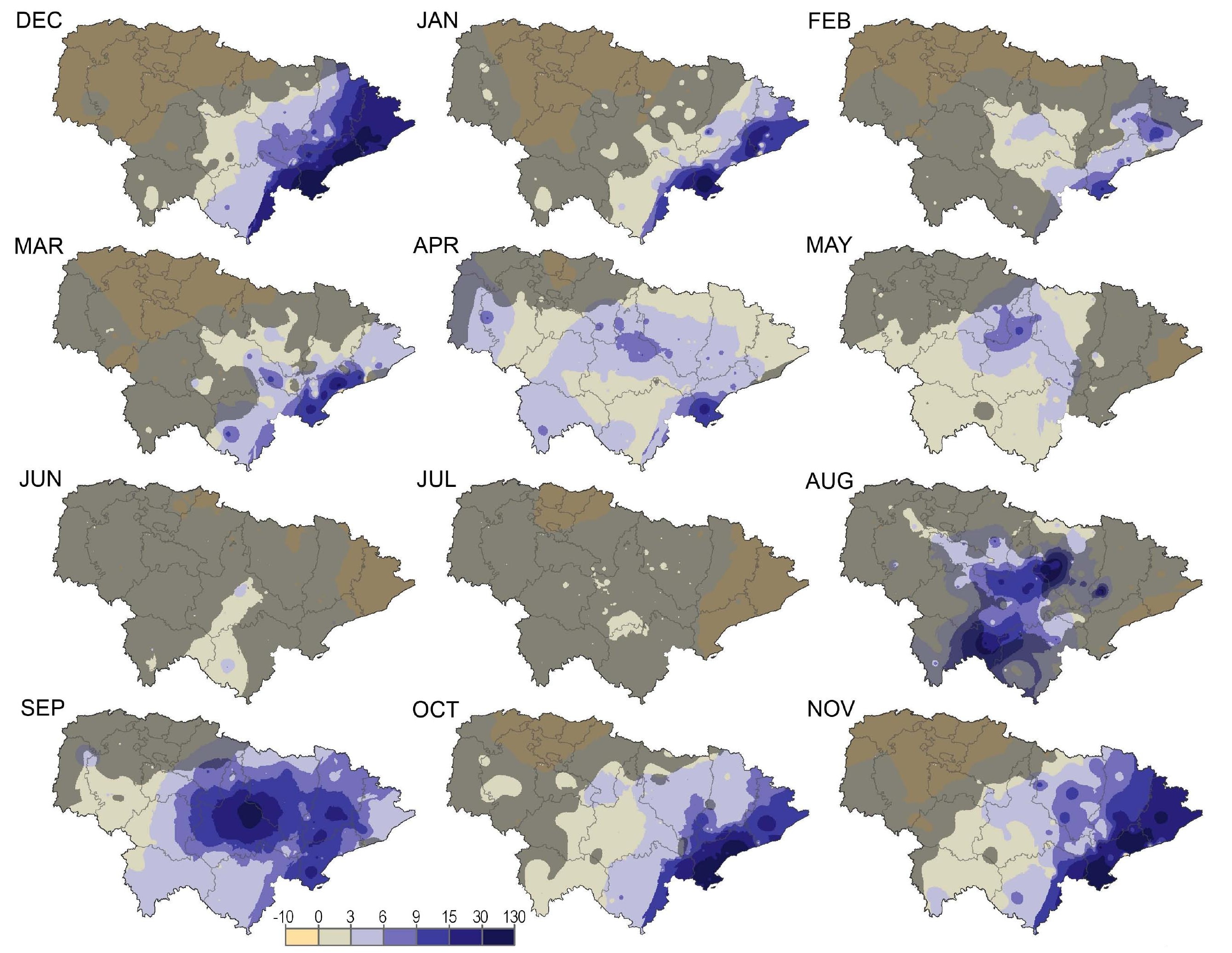


$\mathrm{NAO}^{-}$

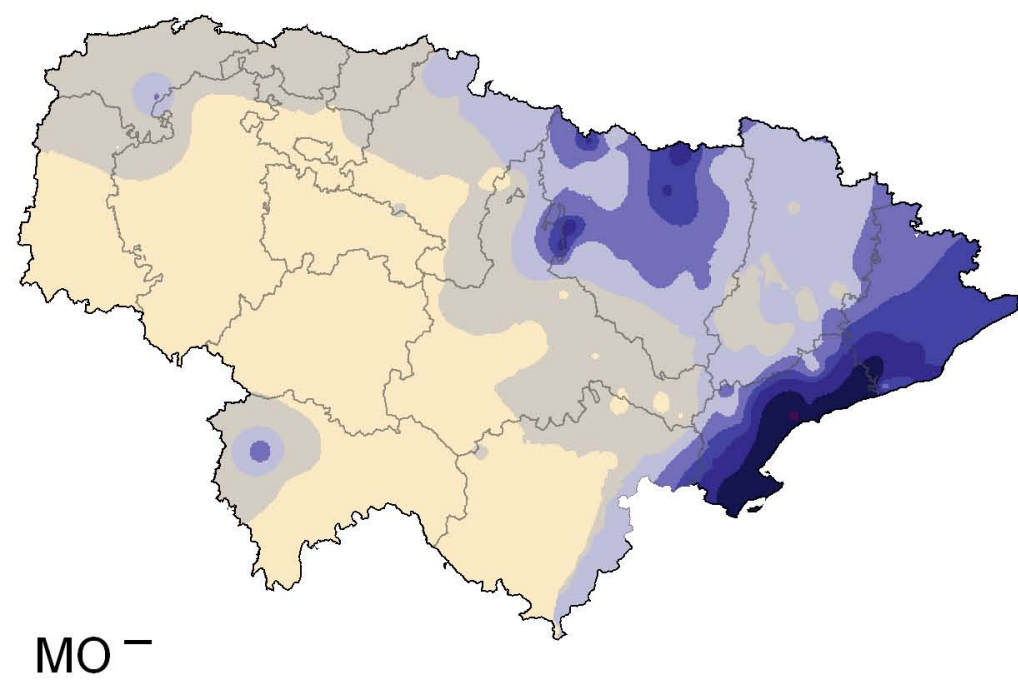

$\mathrm{NAO}^{+}$
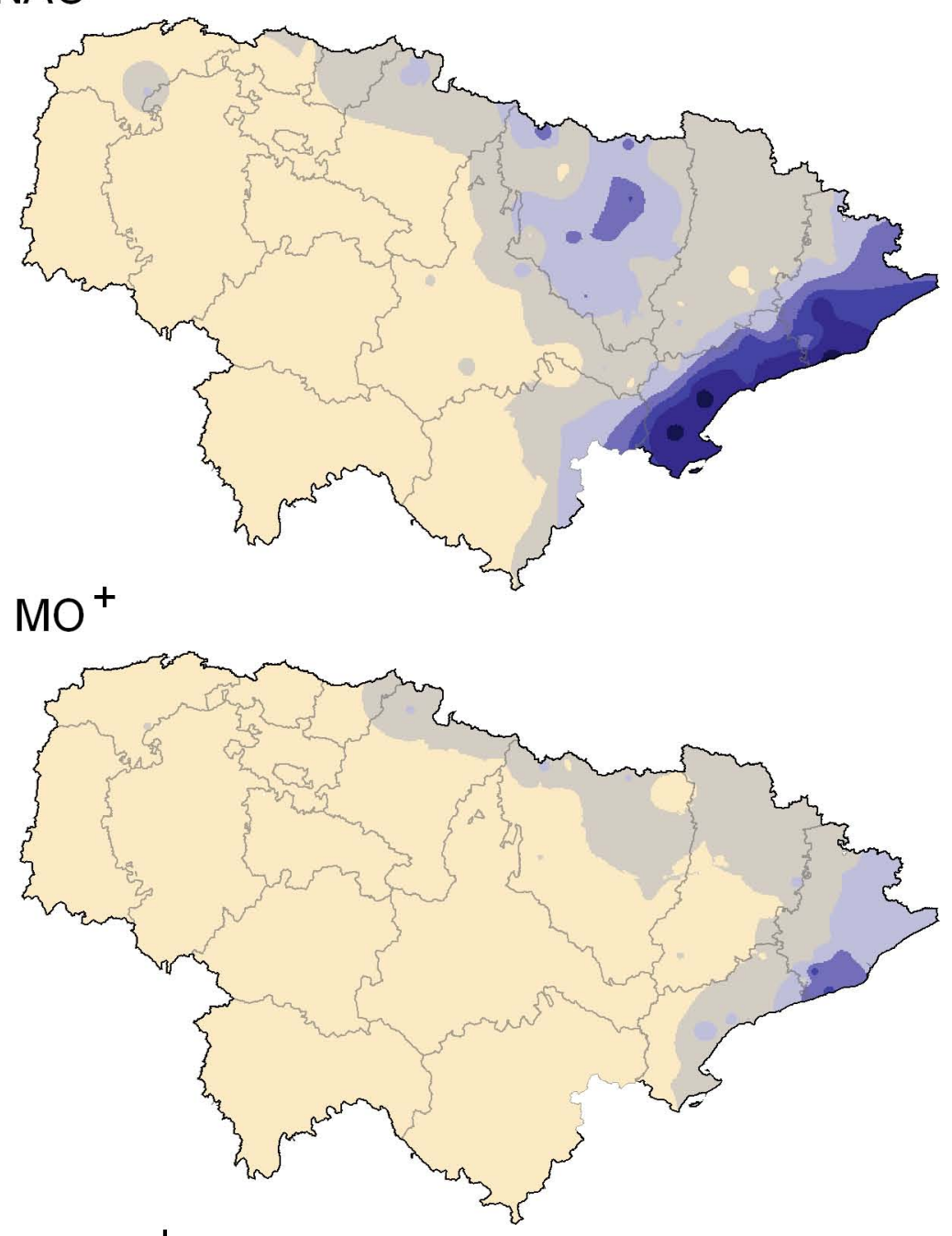

WEMO ${ }^{+}$
WEMO-

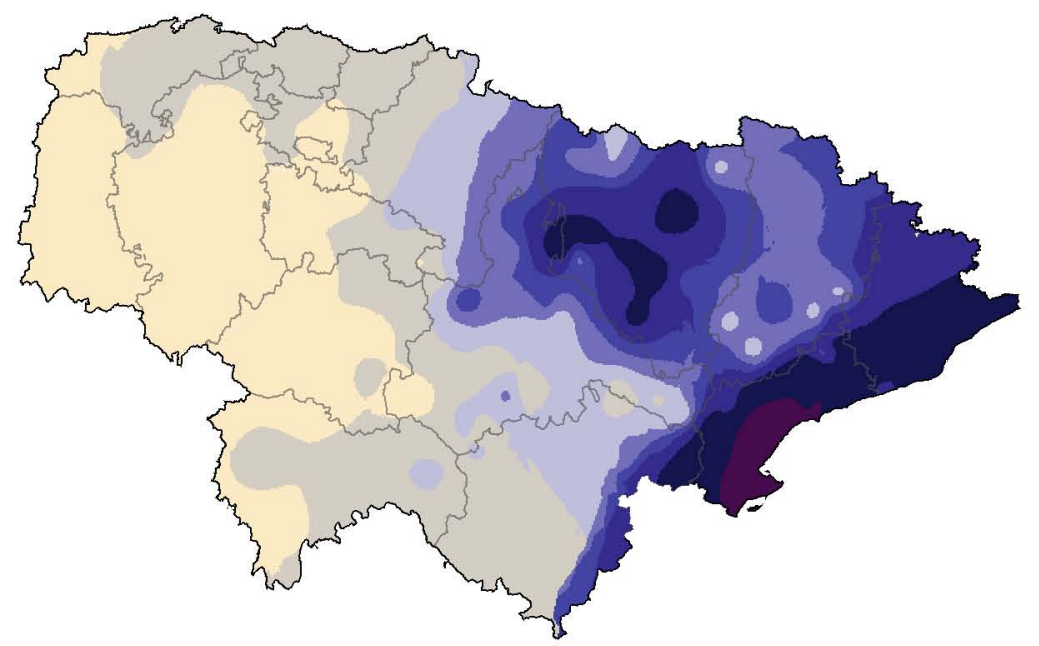

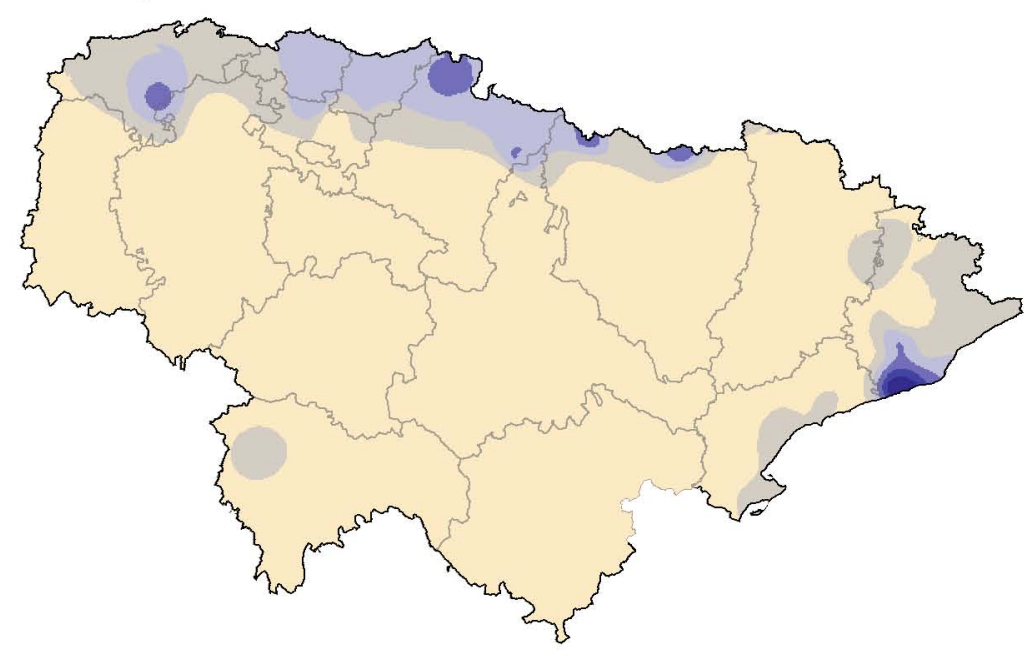




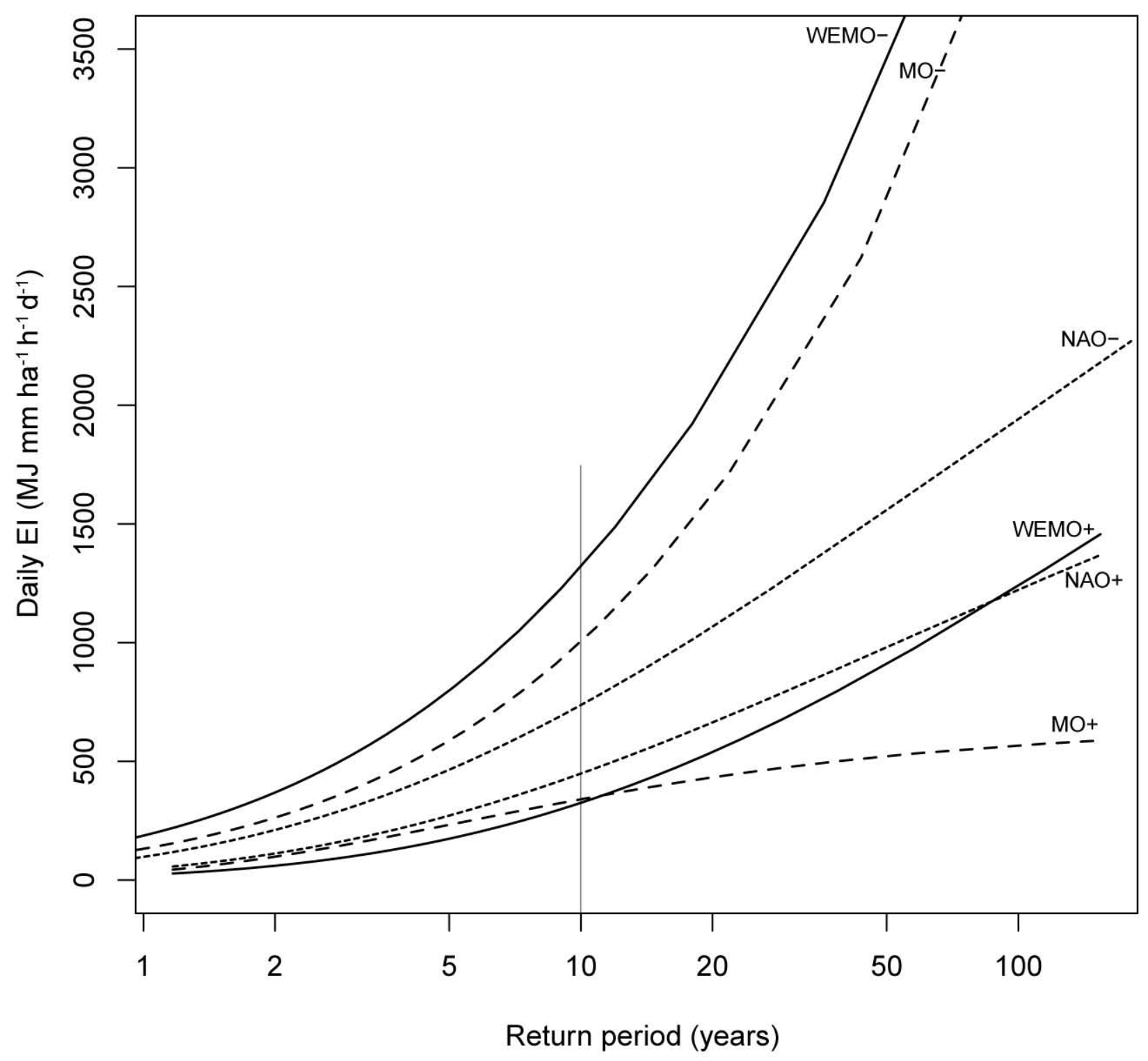

